\title{
Modeling Cryptocurrency (Bitcoin) using Vector Autoregressive (Var) Model"
}

\author{
S. Sathyanarayana ${ }^{1 *}$ and Sudhindra Gargesa ${ }^{2}$ \\ 1Professor, M P Birla Institute of Management, Bengaluru - 560001, Karnataka, India \\ ${ }^{2}$ Professor, Joint Director, M P Birla Institute of Management, Bengaluru - 560001, Karnataka, India
}

\begin{abstract}
A digital currency in which encryption techniques are used to regulate the generation of units of currency and verify the transfer of funds, operating independently of a central bank. Therefore, Bitcoin is a form of digital currency that was designed by Satoshi Nakamoto (an unknown author of Bitcoin white paper 2008) and since then it has able to generate a considerable attention from investors due to its decentralized characteristics and the technology (block-chain) behind it. Bitcoin is a form of digital peer-to-peer currency system where transactions take place without a central bank. The transactions are verified by the nodes of the network and recorded in the Blockchain. Since the popularization of Bitcoin, this technology has caught attention of several technology companies who started to do research on the applications and opportunities of this technology. In this paper, an attempt has been made to capture the time varying variance of most prominent Cryptocurrency Bitcoin with world's top traded currencies such as USD, GBP, Euro, Yen and CHF. In order to realise the stated objectives the researchers have collected the data from Prowess and Yahoo finance database from September 2013 till March 2018. In the first phase the collected data has been for normality and stationarity. Bitcoin was modelled for GARCH and EGARCH tests to capture the time varying volatility and leverage effect. Later the Johansen cointegration test has been conducted to find out the existence of cointegration between the top global currencies with Bitcoin. In the last phase the VECM has been run to capture the both long run and short relationship between Bitcoin and top five traded currencies. In the last phase Variance Decomposition has been run to capture the variance explained by the prominent global currencies on Bitcoin. Both USD and GBP share long run relationship with Bitcoin. Finally, the results have been compared with the possible evidence.
\end{abstract}

Keywords: Cryptocurrency, Blockchain, Stationarity, VAR, Impulse Response Function

\section{Introduction}

Currency is normally accepted form of money, covering paper notes and coins. Currency in general is a system of money in terms of monetary units in common use, which is issued by a government and circulated particularly in a nation. Today, however, the major chunk of currencies are often called as "fiat" currencies, meaning that these currencies are neither inherently valuable nor redeemable for a product or a service but, instead, are issued and sponsored by some central authority such as the Reserve bank of India. The value of such fiat currencies is derived from the trust placed in the central authority by the users of the currency (Seetharaman, A, et al., 2017)). Currency forms as a basis of trade and used as a medium of exchange for goods and services in an economy. Across the globe the central bank of a particular nation has the solitary right to issue currency for circulation. Therefore, money is normally recognised as payment for goods and services in human transaction. No one knows the exact origin of money, however, the researchers seem to agree to the point that the oldest form of money has been bartering. It is very difficult to trace the origin of the invention of money and the transition from "barter systems" to the "monetary systems". One of the major revolutions in the field of monetary system is cryptocurrency. 
Cryptocurrency refers to a math-based, decentralised convertible virtual currency that is protected by cryptography Narayanan et al. (2016). According to Dwyer, (2014) "Bitcoin and similar digital currencies are called crypto-currencies by some because the underlying algorithms and security are intimately related to digital cryptographic algorithms." According to Sheridan (2011), Bitcoin is a private digital currency traded online via a peer-to-peer network and is open source based. It is very clear from the above definition that cryptography and anonymity of the transaction are perceived to be very vital tools to support privacy and freedom in the digital era (Hughes, 1993, \& Stephenson, 1999). Cryptocurrency is a monetary system of currency system that is not governed by governmental rules or law or regulations, making it invulnerable to interference by any government. The supply side of Bitcoin comes from a process called mining. Bitcoin mining is the procedure by which transactions are verified and added to the public ledger and also the means through which new Bitcoin are released. In order to earn Bitcoin one must crack very complicated puzzles. This process of mining bitcoins, however, will not continue forever as there is a cap of 21 million numbers.

Bitcoin mining was designed to mimick the extraction of gold or other precious metals from the earth only a limited, known number of bitcoins can ever be mined. Generally, a digital ledger called blockchain in which all the transactions made in cryptocurrencies such as Bitcoin, Vchain, Ethereum etc. are recorded chronologically and publicly (2015); Morris, D Z (2016); Popper, Nathan (2016). Blockchain is a decentralized transaction and data management technology developed first for Bitcoin cryptocurrency Yli-Huumo, J, et al. (2016). On 31 October 2008, at New York Time (Vigna-Casey, 2015) a seminal paper, written by Satoshi Nakamoto, came with a million-dollar question to the computer programmers across the globe how to design a protocol for a peerto-peer cryptocurrency, called Bitcoin (Extance, 2015; Popper, 2015) (Burnett, John, 2015). The dawn of Bitcoin dealings also marks the commencement of the blockchain technology, a protocol where the pertinent information is recorded in subsequent blocks on a ledger that is shared by all the nodes of the network (Halaburda-Sarvary, 2016). Later, numerous private cryptocurrencies have been introduced such as Litecoin (creator Charlie Lee), SwiftCoin (creator Daniel Bruno) Dash (Evan Duffield \& Kyle Hagan), Ripple, Zcash, Monero (created by Monero Core Team) IOTA etc. and platforms such as s Ethereum, based on blockchain have been introduced (Walport, 2015; Deloitte, 2016, \& Swann, 2015). As on March 16, 2018 there are about 1,658 cryptocurrencies, according to investing.com (Frankel, M, 2018)).

Decentralized cryptocurrencies like Bitcoin, Vchain, Ripple and Ethereum have strong benefits over centralized traditional fiat currencies, mainly because of their capability to function and operate without a single point of failure, except the threat of potential hackers. The arguments in favour of cryptocurrency is that Bitcoin, is not necessarily as a replacement for traditional currencies, but rather as a new payments system. Since there is no third-party intermediary, cryptocurrency dealings are considerably inexpensive and faster than traditional payment system. It is expected to lower the transaction costs for small businesses firms. According to Pflaum and Hateley, (2014). Bitcoin has positioned itself as a lowcost alternative compared to traditional payment system. Another advantage associated with Bitcoin is that they are digital and cannot be counterfeited (Christian, B \& Beat, W, 2014)). Through cryptocurrency one can prevent identity theft. Another major advantage of cryptocurrency is that it reduces the time involved in the traditional asset transfers by eliminating the number of third parties in the transaction as they function like a large property rights database. There are about 2.2 billion individuals, with access to the Internet through mobile phones, who do not currently have access to traditional exchange systems. Therefore, through cryptocurrency they can own a Bitcoin wallet and transfer funds to meet the beneficiaries' micro financing requirements. In the words of Paul Vigna the blockchain keeps everyone honest, and a whole layer of banking bureaucracy is removed, lowering costs. Overall, cryptocurrencies have a long way to go before they can substitute traditional currencies and credit cards as a tool for trade and commerce. Bitcoin is a still in nascent state, it needs years and years of exposure, before the masses 
start accepting it. Therefore, blockchain has the ability to create or to be adopted for new business applications such as smart contract, crowd-funding, transparent governance, supply chain auditing, file storage, protection of intellectual property, Anti-money laundering and 'know your customer' practices.

However, on the flipside, there is no perfect way to guard your bitcoins from human error for example passwords, technical malfunctions for example, hard drive failures, malware or fiduciary fraud. Increased regulations from the states may dampen the currency's values. Yet another important risk associated with the investment in Bitcoin is the high degree of volatility. According to Aleksander Berentsen and Fabian Schär (2018) Bitcoin, is expected to emerge as their own asset class and therefore, have all the potential to grow into an investment and diversification instrument in a portfolio. Therefore, it is opined that liberalisation of rigid predetermined supply of Bitcoin would lead to stability in the price.

The structure of the current empirical paper is as follows: Section two deals with the review of previous literature available to the proposed title of the study. Section three outlines the proposed objectives of the study and the research methodology employed. Section four discusses the analysis and inference drawn from the collected data and in the last phase, a brief discussion, conclusion drawn and the findings of the study has been compared with the possible evidence.

\section{Literature Review}

Since the concept of digital currency such as Bitcoin is of a recent origin, there has been a little but steady increase in the volume of research activities done in relation to this cryptocurrency. Most of the studies available in the literature pertaining Bitcoin is conceptual and technology of Bitcoin. However, only few studies have been done relating to the factor that have been driving the price of Bitcoin, and its price formation. However, only a handful of exploratory research has been undertaken in this area with the aim of investigating the volatility and factors behind the volatility of Bitcoin's price.
According to European Parliamentary Research Service, 2014, due to its anonymous nature, the cryptocurrency have strengthened the path for illegal activities (Tsukerman, Misha, July (2015)). In World Bank's view, the abstract nature of Bitcoin poses a challenge to regulators. Central banks across the globe have cautioned individuals and institutional investors about the various risks associated with the cryptocurrency (EBA (2013); the Banque de France (2013); Banca d'Italia (2014)); (Sarah R., (2015)). Few countries around the world have set stringent capital controls on the cryptocurrency and most of them have covered it under their existing tax laws. For example, in China, individuals are free to trade Bitcoins however, banks are not permitted to transact with them (European Parliamentary Research Service, 2014). In Russia Bitcoin trading by both Banks and citizens. In Island all foreign exchange transactions with Bitcoin is banned. In order to protect the investors from illegal activities such as money laundering in USA the participants are under obligation to report any such suspicious transactions to the government. Countries such as Japan, Finland, Germany any profit on account of purchase and sale of Bitcoins is taxable (European Parliamentary Research Service, 2014).

As per the citation of Grinberg, Hastings Sci \& Tech L J, (2009), a hacker or group of hackers working under the fictitious name Satoshi Nakamoto generated first "Bitcoin", the world's first digital currency. In the words of Friedrich A. Hayek, Bitcoin (2007) is a private currency provided by private enterprise intended at contesting government controls on the supply of money. Generally traditional currency value are determined not only by market forces but also government policies. However, cryptocurrency does not have the controls of any central bank in charge of the money supply or a central clearing house.

A study conducted by Chen Y. Wu and Vivek K. Pandey (2013), with an intention to investigate Bitcoin's ability to act as an asset in a portfolio along with various asset classes such as currency, gold, real estate, stocks and multiple indices concluded that due to the limited daily transactions of Bitcoins they fail to serve as general medium of exchange. 
In an empirical study, Ciaian et al. (2014) tried to explore the relationship between the price of Bitcoin and other variables such as the demand and supply fundamentals, select global financial indicators such as fluctuations in crude price and the bench mark indices such as Dow Jones and Bitcoin's attractiveness for investors by taking the volume of daily Bitcoin views on Wikipedia as proxy. They conclude that, to a large extent, the price of Bitcoin is determined by the interaction of supply and demand, which are among the key drivers and they did not find any evidence that the financial variables have an effect on Bitcoin's price.

In the words of $\mathrm{Wu}, \mathrm{C}$, Vivek, K, (2013) Bitcoin, although decentralised and not exempt from income tax, majority of the nations have defined Bitcoin as an asset or property for taxing purposes. Therefore, corporate and individual investors cannot use Bitcoin to avoid taxes.

In a study by Plassaras, NA., (2013) argues that the IMF, the premier institution accountable for synchronising the stability of foreign exchange rates, is not well equipped to handle the prevalent use of cryptocurrency in the foreign exchange market. He also suggested that how IMF should bring Bitcoin within IMF's purview.

Majority of the empirical studies relating to Bitcoin and other cryptocurrency have been conducted with an aim of determining the major economic factors affecting the price of Bitcoin aimed at only a few number of variables viz., DJIA, the Nikkei 225 and bullion (gold) i.e., Dyhrberg (2015) and van Wijk (2013).

In an empirical investigation of Bourie et al. (2016) to understand the price returns and volatility changes in Bitcoin US implied volatility index (VIX), a negative relation was found between the US VIX and Bitcoin realized volatility.

In another study, Kristoufek (2013) tried to investigate the relationship between Bitcoin price and the interest in the currency by taking online searches in various websites such as Wikipedia and Google as proxy. He found a strong correlation between the two variables and also a bidirectional causal relationships between the two variables.
In an empirical study, Julio Cesar Soldevilla Estrada (2017) tried to explore the relationship between Bitcoin price realized volatility and the S\&P 500, between Bitcoin price realized volatility and the VIX and between Bitcoin price and Blockchain Google Trends. They concluded that there exists a bidirectional Granger-causality relationship between Bitcoin realized volatility and the VIX at the 5\% significance level, that one cannot reject the hypothesis that Bitcoin weekly price do not 'Granger-causes Blockchain trends and also that one cannot reject the hypothesis that Bitcoin realized volatility do not Granger-causes S\&P 500.

In another study by van Wijk (2013) tried to investigate the relationship between the value of Bitcoin with different stock and commodity indices such as the Euro-Dollar \& Yen- Dollar exchange rates, the DJIA, FTSE, Nikkei and the oil price. The study confirmed that only DJIA has shared a significant relationship with cryptocurrency (Bitcoin) in the long run. The study also documented that DJIA, Euro-Dollar exchange rate and oil prices have shared a significant short term, short run association with the cryptocurrency (Bitcoin).

Similarly, there were several studies that were conducted aimed at understanding 'how online queries of the word "Bitcoin", in various search engines and social networking media, affect the price of Bitcoin. Davies (2014) found that Twitter searches do not have an effect on the volatility of Bitcoin. However, fluctuations in Bitcoin have an impact on the tweets about Bitcoin.

A. Seetharaman et al. (2017) tried to investigate the multiple factors which are impacting Bitcoin. To realise the stated objectives the researchers have employed a partial least squares structural equation model. They concluded that few variables like Technology with features like Security, Privacy and Cost-Effectiveness, along with the Bitcoin Economy are affecting Bitcoin users. Combined these can translate into encouraging the usage of Bitcoin as a mainstream currency competing with fiat currencies.

An empirical study by Burnett, John, (2015) discusses the scope of virtual currency and claims that an innovation from the high-tech world, which allows people in the U.S. and the rest of the world to send 
money instantly without banks, credit card companies or other financial intermediaries.

The International Monetary Fund, the institution responsible for coordinating the stability of foreign exchange rates, is ill-equipped to handle the widespread use of digital currencies in the foreign currency exchange market. It highlights the inability of the Fund to intervene in the event of a speculative attack on a currency by Bitcoin users. This Comment concludes by suggesting two interpretations of the IMF's incorporating document and the Articles of Agreement that would allow it to intervene in the event of such an attack.

However, this is quite appealing to those who are wary of high inflation from badly run monetary policies of central banks (Wu, C, Vivek, K, 2013). The supply that miners can add into the circulation is too limited for widespread use. The currency also lacks a formalized market. (Bob, S, 2013).

The review of literature on the proposed topic cryptocurrency, thus throws light on facts relating to the research gap on the chosen topic. Majority of the existing studies of cryptocurrencies are built by computer scientists or programmers who focus mainly on the viability and safety of these systems and transactions. Only a few or handful of studies relating to covering the economic aspect of cryptocurrencies have been taken up. These models use different frameworks to address different research questions, and often focus on different aspects of cryptocurrencies for example Seetharaman, A, et al. (2017) with determinants of cryptocurrency price, Kristoufek (2013) \& Ciaian, et al. (2014) with fundamental features van Wijk (2013) exchange rate, stock and commodity indices, Julio Cesar Soldevilla Estrada (2017) realised volatility of Bitcoin with the S\&P 500, Bourie et al. (2016) to understand the price returns and volatility changes in Bitcoin US implied volatility index (VIX). However, no academic researchers have attempted to define and model cryptocurrency with VAR modelling technique with conventional currency regime. To this end, this paper develops a general VAR model between the traditional currency regimes with cryptocurrency (Bitcoin). Despite the sensational growth of the cryptocurrency in India, no academic research has focused on this aspect in Indian context. This means that the issue of comparison of cryptocurrency with existing currency regime is a largely unknown factor, making this study exploratory in nature. The present research would make an addition to existing literature on measurement of the relationship between these two proposed variables. With the current empirical reasearch work, researchers want to address the gap and emphsise on the effect of existing currency regime (USD, GBP, Euro, Yen and CHF) with cryptocurrency (Bitcoin). Thus, the researchers want to compare different set of popular currencies that might affect the price of Bitcoin. Furthermore, we are also interested in knowing the long run and short run relationship between the existing currency regimes with digital currency such as Bitcoin.

The main research questions addressed in this study based on the above literature review are as follows:

1. What kind of relationship exists between the traditional currency regime and cryptocurrency with special reference to Bitcoin?

2. Can we predict the Bitcoin prices its volatility by taking the traditional currency as a base?

3. How are these two different currency regime related to each other in both long run and in the short run?

\section{Research Design}

\subsection{Objectives of the Study}

1. To investigate the relationship between five major global currencies namely USD, GBP, Euro, CHF and Japanese Yen with prominent Cryptocurrency Bitcoin;

2. To Model volatility clustering on Bitcoin;

3. To find the long run and short relationship between the top traded currencies (USD, GBP, Euro, CHF and Japanese Yen) and the cryptocurrencies;

4. To investigate the impact of one $\sigma$ shock on USD, GBP with Bitcoin;

5. To model the Variance Decomposition of Bitcoin with reference to USD and GBP and

6. To offer suggestions to the market participants based on this study. 


\subsection{Sources of Data}

As the current empirical study was analytical in nature, the data for the purpose of the study was dependent on secondary sources. In this study the data used for analysis is the adjusted closing price of Bitcoin for the period, September 2013 to March 2018. The daily returns $\mathrm{R}_{\mathrm{t}}$ computed from the collected data has been computed as follows

$R_{t}=\ln \frac{\left[C_{t}\right]}{C_{t-1}}$

Where: $\mathrm{R}_{\mathrm{t}}=$ return on day ' $\mathrm{t}$ '

$\mathrm{C}_{\mathrm{t}}=$ Closing Price on day ' $\mathrm{t}$ '

$\mathrm{C}_{\mathrm{t}-1}=$ Closing Price on day ' $\mathrm{t}-1$ ' and

$\ln =$ natural $\log$ of underlying market series.

\subsection{Data and Plan of Analysis}

For the purpose of the study the data has been collected from yahoo.com and various websites. The researchers have collected data from September 2013 to March 2018. On the very first phase the collected data has been tested for the normality by applying Jarque Bera statistics to investigate the normality assumption of the collected data series (Jarque, Carlos, M \& Bera, A K, (1980) (1981)). On the second phase the collected data has been tested by using ADF test with the null hypothesis the series is non-stationary. The SIC is engaged for lag selection. On the third phase, Johansen cointegration test has been run to observe whether the chosen variables have a common stochastic trend or not Johansen and Juselius (1990). To investigate for cointegration among the variables we have employed both the trace statistics tests (with the null hypothesis of the number of cointegration vectors is $r=r^{*}<k$, vs. the alternative that $r=k$ ) (Johansen, S (1991)) and the maximum eigenvalue. For this purpose, the optimal lags were selected on the basis of VAR model. Later VECM model for USD and GBP has been run to identify the relationship between the variables Maghyereh (2004). For the other two currencies Japanese Yen and Euro Unrestricted VAR has been run Engle and Yoo (1987); Clements and Henry (1995); and Hoffman and Rasche (1996); Naka and Tufte (1997); Maghyereh (2004). However, on the last phase the impact of chosen currencies shocks on Bitcoin returns in terms of orthogonalized impulse response functions is assessed and Variance decomposition has been run (Lütkepohl, H, 2007).

\section{Data Analysis}

In order to investigate the stationarity of the time series data the Augmented Dickey Fuller Test (ADF) has been conducted. ADF test is unit root test to investigate the stationarity of the time series data. Existence of unit roots can cause unpredictable results in the time series data (Fuller, W. A. (1976); Dickey, D.A., Fuller, W.A. (1979); S. E. Said and D. A. Dickey (1984)). The ADF test is generally computed with serial correlation and it can handle more complex models than the Dickey-Fuller test, and it is also more robust. Even though there are several tests are available for testing the existence of unit root, for the present study we have used ADF tests because of their popularity and extensive application in the literature. The ADF stats has been conducted with the following hypothesis: there is a unit root in the time series data. The test specification used for the current study is as follows:

$\Delta \mathrm{Y}_{\mathrm{t}}=\mathrm{b}_{0}+\beta \mathrm{Y}_{\mathrm{t}-1}+\mu_{1} \Delta \mathrm{Y}_{\mathrm{t}-1}+\mu_{2} \Delta \mathrm{Y}_{\mathrm{t}-2}+\ldots . .+\mu_{\mathrm{p}} \Delta \mathrm{Y}_{\mathrm{t}-\mathrm{p}}+\mathrm{u}_{\mathrm{t}}$

\subsection{Normality Test}

In order to determine the normality of the collected time series data The Jarque-Bera test has been conducted as normality is one of the major assumptions for many statistical tests (Jarque, Carlos, M \& Bera, A K, (1980) (1981)). This test tries to equate skewness and kurtosis rather than the mean and the standard deviation of the time series data. The test specification used for the current study is as follows:

$$
\text { Jarque-Bera }=\mathrm{n}\left[(\sqrt{\mathrm{b}} 1)^{2} / 6+(\mathrm{b} 2-3)^{2} / 24\right] .
$$

where, $n$ is the sample size, $\sqrt{ } b_{1}$ is the skewness the sample (expected to be zero implies a symmetric distribution) coefficient, $b_{2}$ is the kurtosis of the sample (it is expected to be three and is said to be mesokurtic). The null hypothesis for the Jarque-Bera test is that the data is normally distributed. From the (Table 2) that USD, GBP, Euro and JP Yen were normally distributed. However, Bitcoin and CHF were not normally distributed. 
Table 1. Unit Room Test

\begin{tabular}{|c|c|c|c|c|c|}
\hline \multicolumn{6}{|c|}{ AUGMENTED DICKEY-FULLER TEST STATISTIC } \\
\hline & \multicolumn{2}{|c|}{ At Level } & \multicolumn{2}{|c|}{ At I order difference } & \multirow[t]{2}{*}{ Test Results } \\
\hline & t-Statistic & Prob.* & t-Statistic & Prob.* & \\
\hline Bitcoin & -2.747020 & 0.2229 & -8.375921 & 0.0000 & $\mathrm{I}(1)$ \\
\hline USD & -0.315179 & 0.7732 & -7.995139 & 0.0000 & $\mathrm{I}(\mathbf{1})$ \\
\hline GBP & -0.740307 & 0.3911 & -10.18729 & 0.0000 & $\mathrm{I}(\mathbf{1})$ \\
\hline Euro & -0.449065 & 0.5157 & -7.686113 & 0.0000 & $\mathrm{I}(1)$ \\
\hline Jap Yen & -2.052760 & 0.5597 & -7.916230 & 0.0000 & $\mathrm{I}(1)$ \\
\hline CHF & -5.178700 & 0.0005 & - & - & $\mathrm{I}(0)$ \\
\hline
\end{tabular}

Analysis: It is evident from (Table 1) that Bitcoin, USD, GBP, Euro and JY were non-stationary at level, when the distribution was first differenced we were able to eliminate the unit root in the time series data and became stationary. However, CHF was stationary at level only.

Table 2. Descriptive Statistics

\begin{tabular}{|l|c|c|c|c|c|c|}
\hline & BITCOIN & USD & GBP & EURO & JPY & CHF \\
\hline Mean & 130461.0 & 64.23020 & 93.76056 & 75.87285 & 1.730951 & 66.89613 \\
\hline Median & 38705.68 & 64.29000 & 96.70900 & 74.96600 & 1.719500 & 67.42100 \\
\hline Maximum & 1163256. & 68.39800 & 103.4790 & 85.29300 & 1.947600 & 70.22500 \\
\hline Minimum & 7821.460 & 59.19500 & 81.42800 & 66.84500 & 1.522800 & 54.89900 \\
\hline Std. Dev. & 233793.0 & 2.423318 & 7.120377 & 4.829030 & 0.114325 & 2.322523 \\
\hline Skewness & 2.761450 & -0.14455 & -0.33301 & 0.426880 & 0.214213 & -2.59524 \\
\hline Kurtosis & 10.35346 & 2.040467 & 1.617551 & 2.276360 & 2.347229 & 13.98040 \\
\hline Jarque-Bera & 193.8197 & 2.301493 & 5.396318 & 2.870455 & 1.397135 & 338.0443 \\
\hline Probability & 0.000000 & 0.316401 & 0.067329 & 0.238061 & 0.497297 & 0.000000 \\
\hline
\end{tabular}

BITCOIN

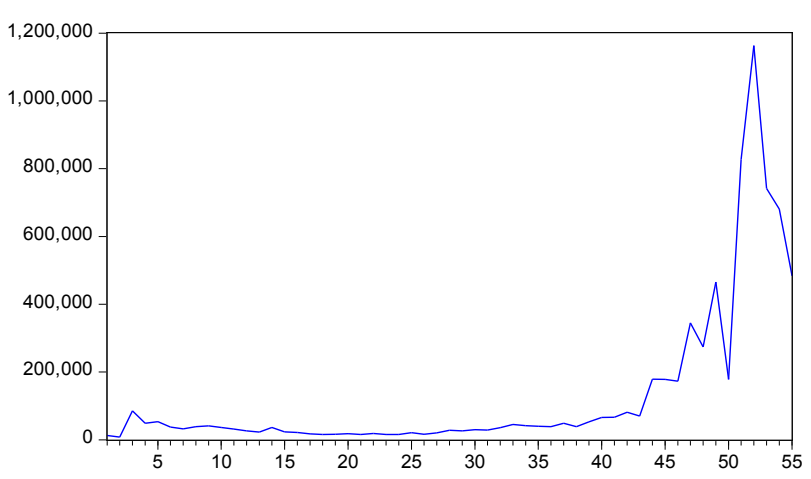

USD

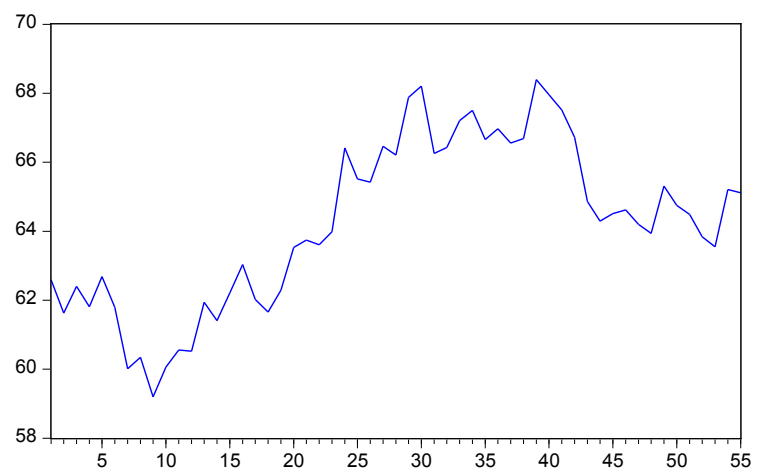


GBP
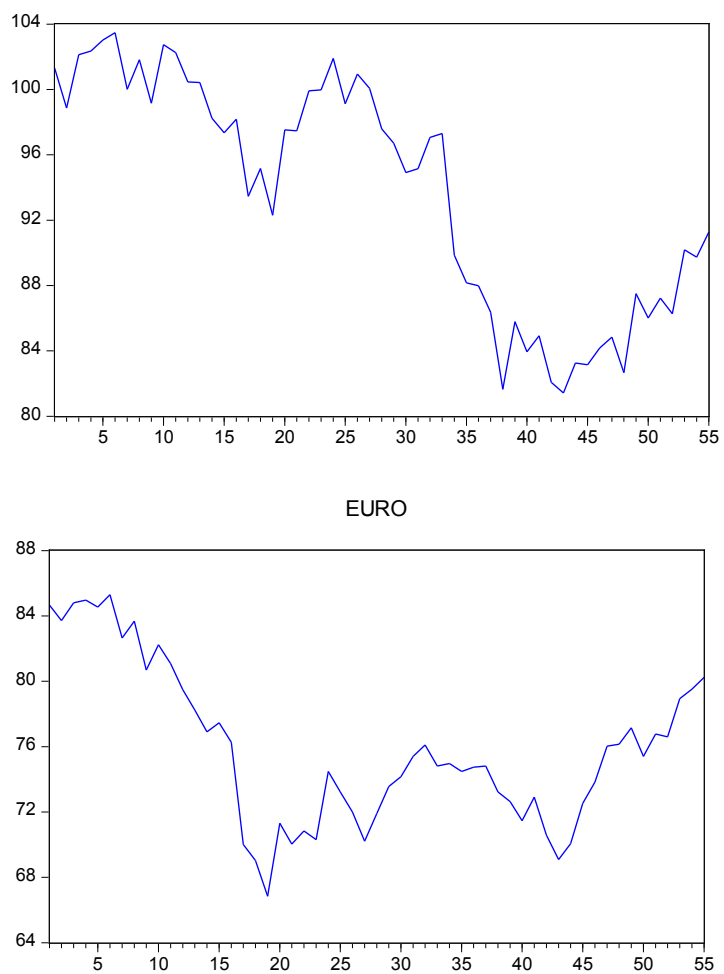

Graph Showing Returns

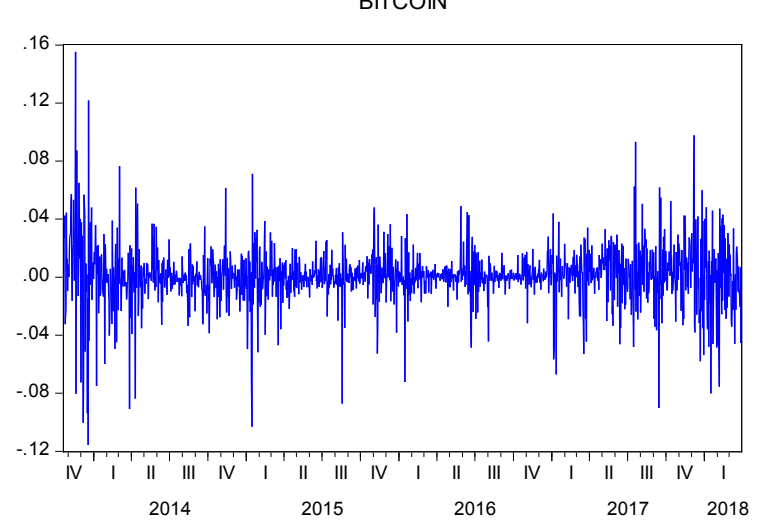

Analysis: It is evident from the above graph that although, the mean was constant for the study period but, one can see the clustering of volatility or time varying variance in the data series. Some periods are highly volatile while others are less. Big shocks (residuals) tend to follow big shocks in either direction and small shocks follow small shocks. This implies strong autocorrelation. Such series are called 'conditionally heteroscedastic'. Therefore, in order to get the pulse, the researcher have conducted Heteroskedasticity: $\mathrm{ARCH}$ test, the following is the test results:
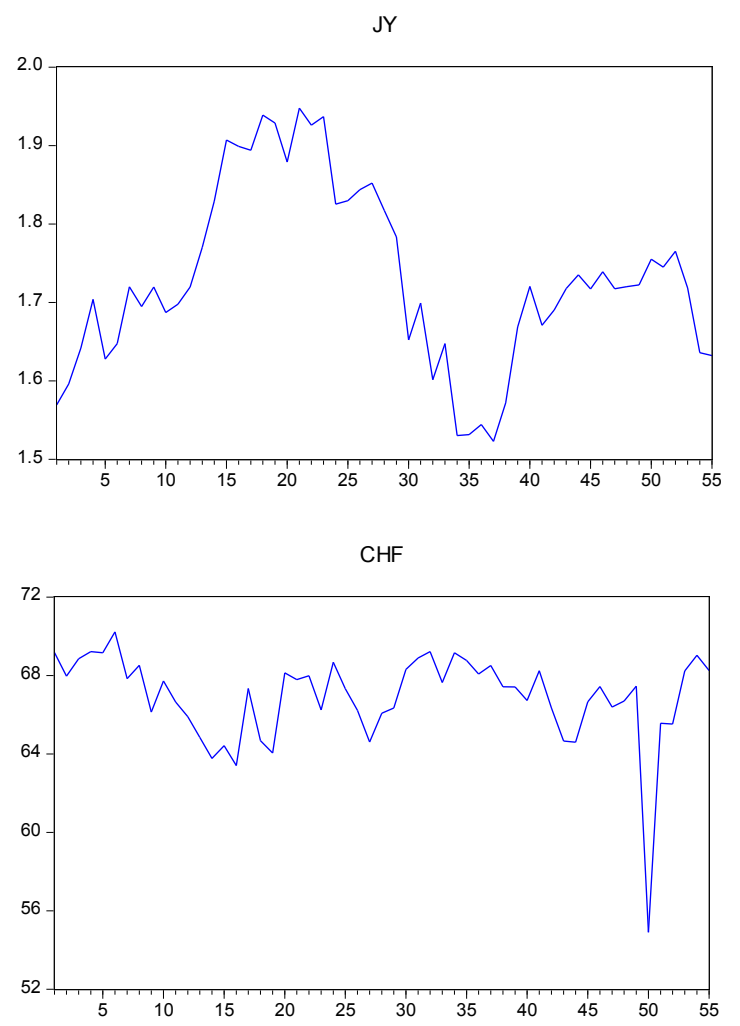

Table 3. Heteroskedasticity Test: ARCH

\begin{tabular}{|l|l|l|l|}
\hline F-statistic & 187.6077 & Prob. F $(1,1618)$ & 0.0000 \\
\hline Obs*R-squared & 168.3226 & Prob. Chi-Square (1) & 0.0000 \\
\hline
\end{tabular}

Analysis: It is evident from the above (Table 3), that the null hypothesis has been rejected meaning that there is an ARCH effect in the collected time series data.

\subsection{Arch and GARCH Modelling}

Since there is a conditional heteroskedasticity in the returns of the Bitcoin, we have modelled the data set by using the generalized autoregressive conditional heteroskedasticity popularly known as GARCH $(1,1)$ process. The GARCH process is developed by Robert F. Engle (1982), to forecast and capture the time varying volatility or Volatility Clustering in financial markets. This models both mean and variance simultaneously. However, the emphasis is more on modelling of variance with an ARCH term: $E\left(u_{t}^{2}\right)=\sigma_{t}^{2}$. Bollerslev (1986) introduced Generalized ARCH (GARCH) model where he defines conditional variance as ARMA process with the following equation:

$$
\sigma_{\mathrm{t}}^{2}=\alpha_{0}+\alpha_{1} \mathrm{u}_{\mathrm{t}-1}^{2}+\alpha_{1} \sigma_{\mathrm{t}-1}^{2}
$$


Table 4. Table showing GARCH $(1,1)$ results

\begin{tabular}{|l|c|c|c|c|}
\hline \multicolumn{5}{|c|}{ Mean Equation } \\
\hline Variable & Coefficient & Std. Error & z-Statistic & Prob. \\
\hline C & 0.000439 & 0.000467 & 0.939291 & 0.3476 \\
\hline \multicolumn{5}{|c|}{ Variance Equation } \\
\hline C & $5.90 \mathrm{E}-05$ & $1.64 \mathrm{E}-06$ & 35.99276 & 0.0000 \\
\hline RESID(-1)^2 & 0.239723 & 0.017983 & 13.33037 & 0.0000 \\
\hline GARCH(-1) & 0.620753 & 0.012359 & 50.22612 & 0.0000 \\
\hline GBP_RETURNS & 0.007887 & 0.001709 & 4.615727 & 0.0000 \\
\hline EUR_RETURNS & -0.004831 & 0.003293 & -1.466841 & 0.1424 \\
\hline CHF_RETURNS & -0.001125 & 0.003811 & -0.295147 & 0.7679 \\
\hline J_YEN_RETURNS & -0.017526 & 0.001764 & -9.934826 & 0.0000 \\
\hline USD_RETURNS & -0.012111 & 0.003340 & -3.626362 & 0.0003 \\
\hline
\end{tabular}

$\mathrm{GARCH}=\mathrm{C}(2)+\mathrm{C}(3) * \mathrm{RESID}(-1)^{\wedge} 2+\mathrm{C}(4) * \mathrm{GARCH}(-1)+\mathrm{C}(5) * \mathrm{GBP}$ RETURNS + C(6)*EUR_RETURNS $+\mathrm{C}(7) *$ CHF_RETURNS $+\mathrm{C}(8) *$ J_YEN_RETURNS + C(9)*USD_RETURNS

Analysis: In the above (Table 4) the $\operatorname{GARCH}(1,1)$ Model shows shows that, at Normal GAUSSIAN distribution, Student $t$ distribution and GED with fixed parameters, the $\mathrm{p}$ value is 0.0000 . Apart from this, the $\mathrm{p}$ value of ARCH 1 (square of previous period 'error term') and GARCH 1 (the previous period conditional variance) are also less than 0.0000 . Indicating that these two shocks are creating volatility in the Bitcoin returns. Apart from that variance regressors such as USD, GBP and JP yen were also significantly contributing the volatility in the Bitcoin.

When we worked out the Correlogram Squared Residual test we found no evidence of autocorrelation in the time series data. When the researchers have conducted Heteroskedasticity Test: ARCH effect in the residuals they found no $\mathrm{ARCH}$ effect in the residuals as the Obs*R-squared was 0.117624 with a Prob. ChiSquare (1) was 0.7316 leading to the acceptance of Null hypothesis.

In order to capture asymmetry in investors' reaction to positive news and negative news the EGARCH model was run by the researchers. EGARCH model was proposed by Nelson (1991). The following is the results of the EGARCH model

Table 5. Table showing EGARCH $(1,1)$ results

\begin{tabular}{|c|c|c|c|c|}
\hline \multicolumn{5}{|c|}{ Mean Equation } \\
\hline Variable & Coefficient & Std. Error & z-Statistic & Prob. \\
\hline$C$ & 0.000854 & 0.000301 & 2.841362 & 0.0045 \\
\hline \multicolumn{5}{|c|}{ Variance Equation } \\
\hline$C(2)$ & -0.583254 & 0.045018 & -12.95598 & 0.0000 \\
\hline$C(3)$ & 0.304099 & 0.019183 & 15.85266 & 0.0000 \\
\hline$C(4)$ & 0.002680 & 0.009927 & 0.269988 & 0.7872 \\
\hline$C(5)$ & 0.953977 & 0.004514 & 211.3257 & 0.0000 \\
\hline$C(6)$ & 26.16305 & 4.035079 & 6.483901 & 0.0000 \\
\hline $\mathrm{C}(7)$ & -13.81508 & 10.36443 & -1.332932 & 0.1826 \\
\hline$C(8)$ & -6.620365 & 7.994119 & -0.828154 & 0.4076 \\
\hline$C(9)$ & -33.44744 & 5.935802 & -5.634864 & 0.0000 \\
\hline$C(10)$ & -19.94884 & 10.01962 & -1.990978 & 0.0465 \\
\hline
\end{tabular}


Analysis: In the (Table 4), The EGARCH coefficient $\lambda$ is significant meaning that there is an information asymmetry and leverage effect while capturing the information by the investors.

Table 6. Table showing VAR LAG order selection criteria

\begin{tabular}{|c|c|c|c|c|c|c|}
\hline Lag & $\log L$ & LR & FPE & AIC & SC & $\mathrm{HQ}$ \\
\hline 6 & -631.1978 & $15.98292^{*}$ & $4.94 \mathrm{e}+09^{\star}$ & $27.96587^{\star}$ & $28.98935^{\star}$ & $28.35101^{*}$ \\
\hline 5 & -738.7120 & $41.92744^{\star}$ & $5.71 e+10^{*}$ & $30.42848^{*}$ & $31.26977^{\star}$ & $30.74885^{\star}$ \\
\hline 5 & -545.9473 & $43.40275^{\star}$ & $25565701^{*}$ & $22.71789^{\star}$ & $23.55918^{*}$ & $23.03826^{\star}$ \\
\hline 5 & -719.9071 & $49.80410^{\star}$ & $2.69 e+10^{*}$ & $29.67629^{*}$ & $30.51758^{\star}$ & $29.99665^{\star}$ \\
\hline
\end{tabular}

It is evident from the (Table 6) that the the Final Prediction Error criterion (FPE), the Akaike information criterion (AIC), the Schwarz information criterion (SC) and the Hannan-Quinn information criterion (HQ) backing 6 lags between Bitcoin and USD and between Bitcoin \& other currencies (GBP, JPY and Euro) 5 lags a higher-order lag length of five months, further analyses were based on six and five lag length criteria.

\subsection{VAR Model} lag order selection approach has been applied to choose the optimum number of lags, we used VAR lag order selection criteria (Braun and Mittnik (1993)). The following (Table 6) shows the test results.
Since the data were integrated at first order, the VAR

\subsection{Johansen Cointegration Test}

Since the data were integrated at first order, the Johansen test of cointegration has been run to assess the long run causality between the currencies (Johansen, Søren 1991). The Johansen tests are also called as the maximum eigenvalue test and the trace test. The following is the output.

Table 7. Johansen cointegration test results

\begin{tabular}{|c|c|c|c|c|c|}
\hline \multicolumn{6}{|c|}{ Unrestricted Cointegration Rank Test (Trace) } \\
\hline & $\begin{array}{l}\text { Hypothesized } \\
\text { No. of CE(s) }\end{array}$ & Eigenvalue & Trace Statistic & 0.05 Critical Value & Prob.** \\
\hline \multirow[t]{2}{*}{ Bitcoin and USD } & None * & 0.341253 & 22.58504 & 15.49471 & 0.0036 \\
\hline & At most 1 & 0.042571 & 2.131685 & 3.841466 & 0.1443 \\
\hline \multirow[t]{2}{*}{ Bitcoin and GBP } & None * & 0.330082 & 19.84774 & 15.49471 & 0.0103 \\
\hline & At most 1 & 0.004447 & 0.218368 & 3.841466 & 0.6403 \\
\hline \multirow[t]{2}{*}{ Bitcoin and JPY } & None * & 0.236432 & 20.05408 & 15.49471 & 0.0096 \\
\hline & At most 1 & 0.130219 & 6.836204 & 3.841466 & 0.0089 \\
\hline \multirow[t]{2}{*}{ Bitcoin and Euro } & None * & 0.428451 & 37.97279 & 15.49471 & 0.0000 \\
\hline & At most 1 & 0.193902 & 10.56193 & 3.841466 & 0.0012 \\
\hline \multicolumn{6}{|c|}{ Unrestricted Cointegration Rank Test (Maximum Eigenvalue) } \\
\hline & $\begin{array}{l}\text { Hypothesized } \\
\text { No. of CE(s) }\end{array}$ & Eigenvalue & Trace Statistic & 0.05 Critical Value & Prob.** \\
\hline \multirow[t]{2}{*}{ Bitcoin and USD } & None * & 0.341253 & 20.45336 & 14.26460 & 0.0046 \\
\hline & At most 1 & 0.042571 & 2.131685 & 3.841466 & 0.1443 \\
\hline \multirow[t]{2}{*}{ Bitcoin and GBP } & None * & 0.330082 & 19.62937 & 14.26460 & 0.0064 \\
\hline & At most 1 & 0.004447 & 0.218368 & 3.841466 & 0.6403 \\
\hline \multirow[t]{2}{*}{ Bitcoin and JPY } & None * & 0.236432 & 13.21787 & 14.26460 & 0.0727 \\
\hline & At most 1 & 0.130219 & 6.836204 & 3.841466 & 0.0089 \\
\hline \multirow[t]{2}{*}{ Bitcoin and Euro } & None * & 0.428451 & 27.41086 & 14.26460 & 0.0003 \\
\hline & At most 1 & 0.193902 & 10.56193 & 3.841466 & 0.0012 \\
\hline
\end{tabular}

* denotes rejection of the hypothesis at the 0.05 level

**MacKinnon-Haug-Michelis (1999) p-values 
Analysis: It is evident from the above (Table 7) that both Trace statistics and Maximum Eigenvalue test results revealed that there exists a long term relationship between Bitcoin \& USD and Bitcoin \& GBP. Both Unrestricted Cointegration Rank Test (Trace) and Unrestricted Cointegration Rank Test (Maximum Eigenvalue) show the presence of one cointegration equation at 0.05 level. However, both
Unrestricted Cointegration Rank Test (Trace) and Unrestricted Cointegration Rank Test (Maximum Eigenvalue) reject the existence of any cointegration equation between Bitcoin \& JP Y and Bitcoin \& Euro. Therefore, the researcher conducted VECM test for Bitcoin \& USD, GBP and unrestricted VAR test the short-run relationship among Bitcoin and JP Y and Euro.

Table 8. VECM (Vector Error Correction Model) Test Results

\begin{tabular}{|l|c|c|c|c|c|}
\hline & & Coefficient & Std. Error & t-Statistic & Prob. \\
\hline LR relationship equation Bitcoin and USD & $\mathrm{C}(1)$ & -2.187977 & 0.517248 & -4.230035 & 0.0001 \\
\hline LR relationship equation Bitcoin and GBP & $\mathrm{C}(1)$ & -0.278659 & 0.100797 & -2.764556 & 0.0022 \\
\hline
\end{tabular}

Analysis: It is evident from the above (Table 8) that the long run coefficient is significant at one percent for both USD and GBP indicating the long run relationship between Bitcoin and USD and GBP. However, for short run causality lag 1 , lag 2 , lag 3 , lag 4 and lag 5 of Bitcoin was significant and lag 1, lag 2, lag 3, lag 4 and lag 5 of USD was not statistically significant with Bitcoin. For short run causality lag 1, lag 2, lag 3 and lag 4 of Bitcoin was significant and lag 1, lag 2, lag 3 and lag 4 of GBP were not statistically significant with Bitcoin. Indicating the only Bitcoin lags are relevant for the short run relationship.

In the next phase in order to investigate the joint effect of lags (both USD \& Bitcoin and GBP \& Bitcoin) Wald statistics (Engle, Robert F. (1983)) was run by the researchers with the following Hypothesis $\mathrm{C}(2)=\mathrm{C}(3)$ $=\mathrm{C}(4)=\mathrm{C}(5)=\mathrm{C}(6)=0$. The following is the results.

Table 9. WALD test results

\begin{tabular}{|l|l|c|c|c|}
\hline & \multicolumn{1}{|c|}{ Test Statistic } & Value & df & Probability \\
\hline \multirow{2}{*}{ Lags (Bitcoin) } & F-statistic & 21.81958 & $(5,37)$ & 0.0000 \\
\cline { 2 - 5 } & Chi-square & 109.0979 & 5 & 0.0000 \\
\hline \multirow{2}{*}{ Lags (USD) } & F-statistic & 0.821567 & $(5,37)$ & 0.5423 \\
\cline { 2 - 5 } & Chi-square & 4.107835 & 5 & 0.5340 \\
\hline \multirow{2}{*}{ Lags (Bitcoin) } & F-statistic & 15.39334 & $(5,39)$ & 0.0000 \\
\cline { 2 - 5 } & Chi-square & 76.96671 & 5 & 0.0000 \\
\hline \multirow{2}{*}{ Lags (GBP) } & F-statistic & 0.723568 & $(5,39)$ & 0.4421 \\
\cline { 2 - 5 } & Chi-square & 3.917631 & 5 & 0.4912 \\
\hline
\end{tabular}

Analysis: It is evident from the above (Table 9) that $\mathrm{C}(2)=\mathrm{C}(3)=\mathrm{C}(4)=\mathrm{C}(5)=\mathrm{C}(6) \neq 0$. Meaning that together they are not zero so there is a short run association or causality between lags of Bitcoin and Bitcoin so there is a short run association or causality between Lags of Bitcoin and Bitcoin. However, for USD we failed to reject the Null hypothesis indicating that there is no short run causality running from lags of USD and Bitcoin. $C(2)=C(3)=C(4)=C(5) \neq 0$. Meaning that together they are not zero so there is a short run association or causality between lags of Bitcoin and Bitcoin. However, for GBP we failed to reject the Null hypothesis indicating that there is no short run causality running from lags of GBP and Bitcoin. 


\subsection{Impulse Response Test Function}

Granger-causality alone may not reveal the complete clarity about the interactions between the variables under VAR environment. In real world scenario the researchers is often interested in knowing the response of one variable to an impulse in another variable (Hamilton J D, 1994). Apart from this Impulse Response Functions (IRF) represent the mechanisms through which shock spread over

Graph 1. Graph showing impulse response function time. Therefore, in econometrics, any function that describes the cascade of future changes due to an unpredicted one standard deviation shockwave in period $t\left(\mathrm{Y}_{\mathrm{t}}\right)$ is known as the impulse-response function. For computation of IR, the ordering of the variables is very important. In the current study we shall be using Cholesky's dof adjusted Model for setting the ordering of the variables.

Response to Cholesky One S.D. Innovations \pm 2 S.E.
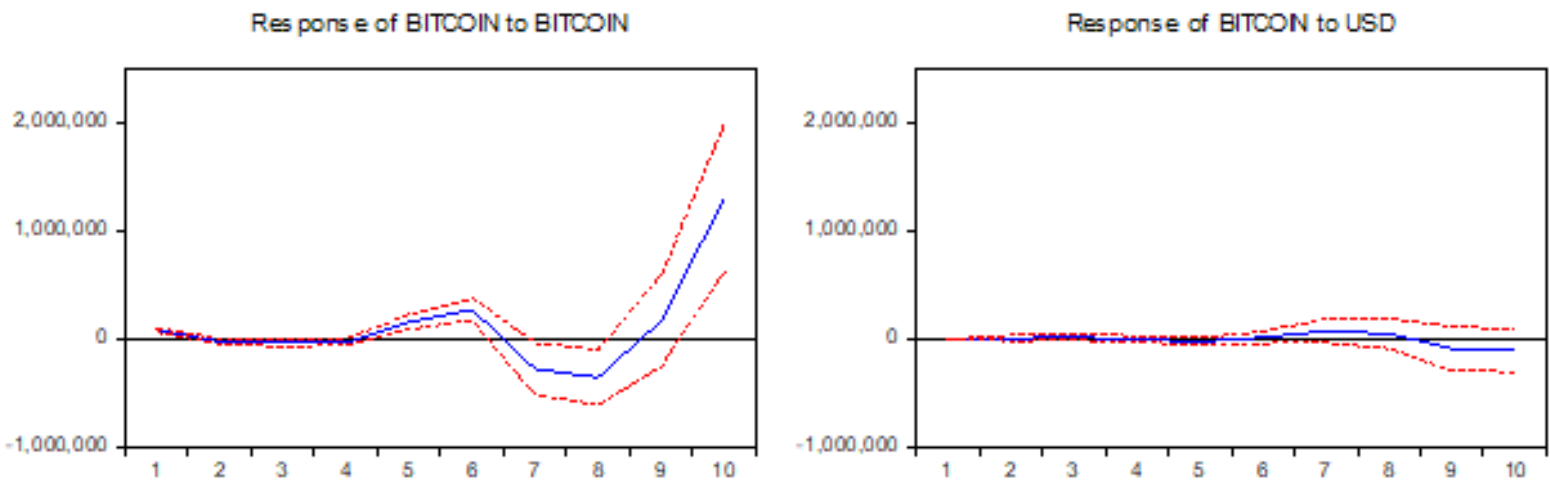

Response to Cholesky One S.D. Innovations \pm 2 S.E.
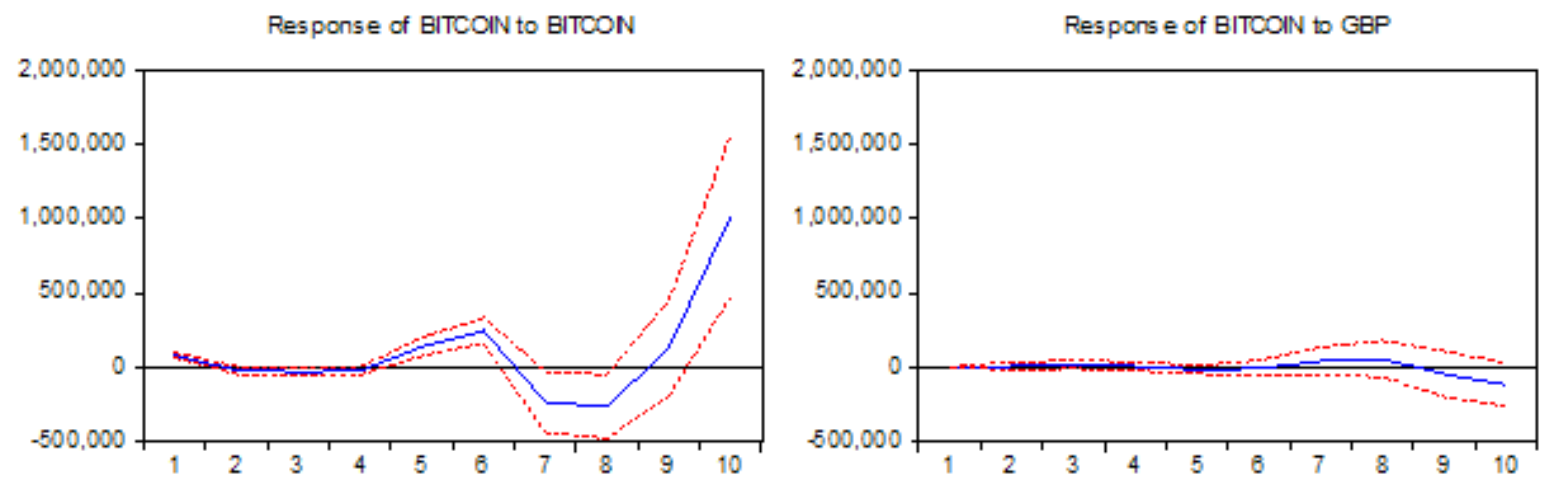

Analysis: A shock in Bitcoin and its impact on

Analysis: A standard deviation shock in Bitcoin Bitcoin (internal shock) Blue line going down initially its positive and later it becomes negative and recovers from the shock month five and six later it reaches negative till $9^{\text {th }}$ month and recovers from the shock reaches the positive trend. However, a standard deviation shock by USD is affecting Bitcoin it is almost stable for the first six months later, it fluctuates and reaches negative at the end of ninth month. and its impact on Bitcoin (internal shock) Blue line going down initially its positive and later it becomes negative and recovers from the shock month five and six later it reaches negative till $9^{\text {th }}$ month and recovers from the shock reaches the positive trend. However, a standard deviation shock by GBP affecting Bitcoin it is almost stable for the first six months later, it fluctuates and reaches negative at the end of ninth month. 


\subsection{Variance Decomposition in VAR}

A variance decomposition or Forecast Error Variance Decomposition (FEVD) is used to aid in the interpretation of a vector autoregression (VAR) model once it has been fitted (Lütkepohl, H, 2007).

The variance decomposition indicates the amount of information each variable contributes to the other variables in the autoregression. It determines how much of the forecast error variance of each of the variables can be explained by exogenous shocks to the other variables. In simple words, VD helps in the interpretation of the VAR model once it has been fitted. It helps to determine the proportion of variation of the dependent variable explained by each of the independent variables.

Table 10. The Autoregressive Distributed Lag Test Results

\begin{tabular}{|c||c|c|c||c|c|c|c||}
\hline \multicolumn{5}{|c|}{ VD of BITCOIN with USD } & \multicolumn{3}{c||}{ VD of BITCOIN with USD } \\
\hline Period & S.E. & BITCOIN & USD & Period & S.E. & BITCOIN & USD \\
\hline 1 & 73918.91 & 100.0000 & 0.000000 & 1 & 75025.53 & 100.0000 & 0.000000 \\
\hline 2 & 75806.08 & 98.11981 & 1.880193 & 2 & 76774.78 & 98.60260 & 1.397403 \\
\hline 3 & 81484.77 & 93.02299 & 6.977008 & 3 & 80508.18 & 97.93463 & 2.065370 \\
\hline 4 & 85932.65 & 93.15313 & 6.846869 & 4 & 85522.28 & 98.15739 & 1.842614 \\
\hline 5 & 183524.7 & 97.60880 & 2.391202 & 5 & 173717.6 & 98.99400 & 1.005997 \\
\hline 6 & 311486.5 & 99.00433 & 0.995675 & 6 & 294931.1 & 99.64689 & 0.353111 \\
\hline 7 & 435619.1 & 94.87624 & 5.123757 & 7 & 400661.3 & 98.68221 & 1.317791 \\
\hline 8 & 503594.1 & 95.20903 & 4.790970 & 8 & 453819.6 & 98.97260 & 1.027399 \\
\hline 9 & 576483.1 & 91.62166 & 8.378345 & 9 & 501484.0 & 97.80361 & 2.196387 \\
\hline 10 & 1456631. & 98.44102 & 1.558984 & 10 & 1259269. & 99.42150 & 0.578501 \\
\hline
\end{tabular}

Analysis: it is evident from the above (Table 10) that for the short run same for instance, third month impulse or innovation or shock to Bitcoin accounts for $93.02 \%$ variation of the fluctuations in Bitcoin. It's nothing but Bitcoin's own shock. Meaning that the shock in the Bitcoin can cause $93.02 \%$ variation of the fluctuations in Bitcoin. However, shock wave in USD can cause $6.97 \%$ fluctuations in Bitcoin. Similarly, for the long run say for the tenth month, $98.44 \%$ variation of the fluctuations in Bitcoin shall be contributed by Bitcoin's own shock and USD can cause $1.56 \%$ fluctuations in Bitcoin. Similarly, for the third month, impulse or innovation or shock to Bitcoin accounts for 97.93\% variation of the fluctuations in Bitcoin. However, shock wave in GBP can cause $2.07 \%$ fluctuations in Bitcoin. Similarly, for the long run say for the tenth month, 99.42\% variation of the fluctuations in Bitcoin shall be contributed by Bitcoin's own shock and GBP can cause $0.58 \%$ fluctuations in Bitcoin.

\subsection{Unrestricted VAR}

Since the variables Bitcoin, JP Yen and Euro are not cointegrated, the unrestricted VAR model has been developed. The following is the test results.

Table 11. VECM (Vector Error Correction Model) Test Results

\begin{tabular}{|l|c|c|c|c|c|}
\hline & & Coefficient & Std. Error & t-Statistic & Prob. \\
\hline LR relationship equation Bitcoin and JPY & $\mathrm{C}(1)$ & -0.293576 & 0.160474 & -1.829430 & 0.0712 \\
\hline LR relationship equation Bitcoin and Euro & $\mathrm{C}(1)$ & -0.352560 & 0.150065 & -2.349381 & 0.0213 \\
\hline
\end{tabular}

Analysis: It is evident from the above (table 11) that the long run coefficient is not significant at five percent for JP Yen indicating that there is no long run relationship between Bitcoin and JP Yen. However, for short run causality lag 1, lag 2, lag 3 and lag 4 of Bitcoin were statistically significant. Lags of JP Yen were not statistically significant for short run. For Euro, the long run coefficient is significant at five percent indicating 
that there is a long run relationship between Bitcoin and Euro. However, for short run causality past four lags were statistically significant and past lags of Euro were not statistically significant, indicating the only Bitcoin lags are relevant for the short run relationship. In the next phase in order to investigate the joint effect of lags (both USD \& Bitcoin and GBP \& Bitcoin) Wald statistics (Engle, R F, 1983) was run by the researchers. The following is the results.

Table 12. WALD Test Results

\begin{tabular}{|l|l|c|c|c|}
\hline & Test Statistic & Value & df & Probability \\
\hline Bitcoin (Lags) & Chi-square & 372.5976 & 5 & 0.0000 \\
\hline Euro (Lags) & Chi-square & 10.20608 & 5 & 0.0696 \\
\hline Bitcoin (Lags) & Chi-square & 345.4043 & 5 & 0.0000 \\
\hline JPY (Lags) & Chi-square & 2.431702 & 5 & 0.7867 \\
\hline
\end{tabular}

Analysis: All past lag values of Bitcoin together are not equal to zero so that there is a short run association or causality between past lags of Bitcoin and Bitcoin. Past lags of Bitcoin is jointly causing the Bitcoin in the short run. However, for Euro we failed to reject the Null hypothesis indicating that there is no joint short run causality running from lags of Euro and Bitcoin. However, for Japanese Yen we failed to reject the Null hypothesis indicating that there is no joint short run causality running from lags of Yen and Bitcoin.

\subsection{ARDL Model (Bitcoin and CHF)}

The Autoregressive Distributed Lag (ARDL) is an approach in which the econometricians use for testing for the presence of long-run relationships between economic time-series data (Dhrymes, P J, 1971). The basic ARDL regression model is as follows:

$$
\mathrm{y}_{\mathrm{t}}=\mathrm{B}_{0} \mathrm{x}_{\mathrm{t}}+\mathrm{B}_{1} \mathrm{x}_{\mathrm{t}-1}+\mathrm{B}_{2} \mathrm{x}_{\mathrm{t}-2}+\ldots+\mathrm{B}_{\mathrm{k}} \mathrm{x}_{\mathrm{t}-\mathrm{k}}+\mathrm{e}_{\mathrm{t}}
$$

In the above model, $e_{t}$ is a random "disturbance" term. For one-off unit change in $\mathrm{x}$ there is an impact on $\mathrm{y}$; this impact is capture by B0; B1 is the impact on y after one period, B2 is the impact after 2 period, and so on.

For this purpose, Lag length has been determined and we have the least AIC and SIC criteria reported was for 2 lags. Under lag 2 we did not found any serial correlation in the data set with $\mathrm{Obs}^{*} \mathrm{R}$-squared being 1.138087 with a $p$ value of 0.5661 and the following is the stability diagnostics (CUSUM test).

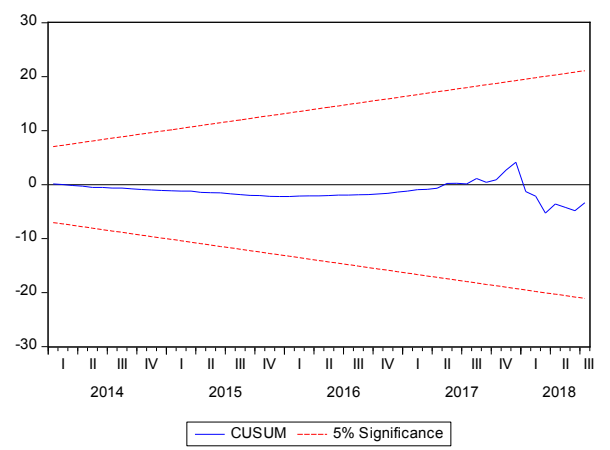

However, when we ran Wald stats, the $\mathrm{F}$ value was 0.539525 and when we compared with Pesaran critical values at 5\%. From the Pesaran Table - our lower bound value is 2.86 and upper value is 4.01 . Since the computed $F$ value is less than the LB critical value we cannot reject the Null. Meaning that there is no long run association between Bitcoin and CHF.

\section{Discussion and Conclusion}

A cryptographic money is a computerized or virtual cash that utilizations cryptography for security. A digital money is hard to fake in light of this security include. Over recent years, interest has been growing in Bitcoin, an innovation which has the potential to play an important role in e-commerce and beyond. The main objective of this empirical paper is to compare existing currency regime with one of the most prominent crypto currency Bitcoin. In order to realize the stated objectives the researchers have collected data from 21st October 2013 to 30th March 2018 from various web sources. On the very first phase the collected data has been tested for the normality and later it has been tested for existence of unit root by running ADF test. Later, GARCH $(1,1)$ model and EGARCH model have been run to capture the conditional heteroscedasticity and information asymmetry. Since the data was integrated at first order Johansen cointegration test has been conducted and VECM model (USD and GBP) and Unrestricted VAR test (Euro and Japanese Yen) has been run. On the last phase Impulse response function and ARDL model has been done to draw conclusion. The current empirical study revealed the following major findings: for Bitcoin the mean returns reported for the study period was Bitcoin was 0.000949 with a Standard Deviation 0.019562. The 
maximum adjusted closing price reported during the study period was 19497.4 and minimum was 68.43 with a range of 19428.97.

GARCH Model shows that, both ARCH and GARCH were significant indicating that these two shocks were creating volatility in the Bitcoin returns. Apart from that variance regressors such as USD, GBP and JP yen were also significantly contributing the volatility in the Bitcoin. The EGARCH coefficient $\lambda$ is significant meaning that there is an information asymmetry and leverage effect while capturing the information by the investors.

Since the data were integrated at first order, the Johansen test of cointegration has been run to assess the long run causality between the currencies (Johansen, S, 1991)). Trace statistics and Maximum Eigenvalue test results revealed that there exists a long term relationship between Bitcoin \& USD and Bitcoin \& GBP. However, both Unrestricted Cointegration Rank Test (Trace) and Unrestricted Cointegration Rank Test (Maximum Eigenvalue) reject the existence of any cointegration equation between Bitcoin \& Yen and Bitcoin \& Euro. The long run coefficient is significant at one percent for both USD and GBP indicating the long run relationship between Bitcoin and USD and GBP. However, for short run causality lag 1 , lag 2 , lag 3 , lag 4 and lag 5 of Bitcoin was significant and lag 1, lag 2, lag 3, lag 4 and lag 5 of USD was not statistically significant with Bitcoin. For short run causality lag 1, lag 2, lag 3 and lag 4 of Bitcoin was significant and lag 1, lag 2, lag 3 and lag 4 of GBP were not statistically significant with Bitcoin. Indicating the only Bitcoin lags are relevant for the short run relationship. For the third month impulse or innovation or shock to Bitcoin accounts for $93.02 \%$ variation of the fluctuations in Bitcoin. It's nothing but Bitcoin's own shock. However, shock wave in USD can cause $6.97 \%$ fluctuations in Bitcoin. Similarly, for the long run say for the tenth month, 98.44\% variation of the fluctuations in Bitcoin shall be contributed by Bitcoin's own shock and USD can cause $1.56 \%$ fluctuations in Bitcoin. Similarly, for the third month, impulse or innovation or shock to Bitcoin accounts for $97.93 \%$ variation of the fluctuations in Bitcoin. However, shock wave in GBP can cause
$2.07 \%$ fluctuations in Bitcoin. Similarly, for the long run say for the tenth month, $99.42 \%$ variation of the fluctuations in Bitcoin shall be contributed by Bitcoin's own shock and GBP can cause $0.58 \%$ fluctuations in Bitcoin.

The current paper has tried to provide empirical support on the recent innovation Bitcoin, which can be considered as a new digital currency that is inseparably linked to a decentralized electronic payment system. But in available literature on topic there is still no understandable theory outlining how Bitcoin should be priced since, by its very nature, it produces no dividends, cash flows or earnings. In the absence of obvious standard valuation approaches. Our results indicate that popularity of this cryptocurrency is one of the main determinant for driving the price of cryptocurrencies. We observed that returns tend to be elevated whenever newspaper articles mention Bitcoin more frequently and whenever the number of people searching for it on Google increases. Moreover, the tone of newspaper articles also influences the value of Bitcoin - unfavourable mentions may have negative consequences, without any exploratory empirical support. More specifically, the method employed here rests upon looking at both the supply-side and the factors that drive demand.

Based on the findings of the current empirical study the following scheme of recommendation is offered by the researcher. Since there is a high degree of concern about the cryptocurrencies in India, it is advisable to the policy makers to take a stand on cryptocurrencies. How it should be treated? If yes, under what asset class? How it should be defined as an asset while taxing? Will it be taxed under the head Profits or Gains from Business or Profession or under the head Capital Gain. A separate machinery to be established to protect the interest if the investors at large. All the above raised research questions involve a major question of how to bring Bitcoin into mainstream regulatory, legal and tax regimes. Answer for the same depending on whether it is seen as a currency, an asset, a commodity or a digital service. Market participants can take investment in cryptocurrencies seriously compared to various risky asset classes as the yield 
recorded by the Bitcoin $363.27 \%$ for the study period. Since the bench mark currencies such as USD, GBP and Euro can cause significant volatility in Bitcoin it is advisable for the participants to watch these currency indices and past four to five lags of the Bitcoin before taking investment decision. It is worth to quote the points of who framed a report for UBS AG and UBS Financial Services Inc. According to the report "while we are doubtful whether cryptocurrencies will ever become a mainstream means of exchange, the underlying technology, blockchain, is likely to have a significant impact in industries ranging from finance to manufacturing, healthcare, and utilities. We estimate that blockchain could add as much as USD $300-400$ billion of economic value globally by 2027 ". Only time will tell as to whether the benefits will overshadow the limitations, and whether acceptance will become widespread, or remain limited to narrow niches and the shadow economy.

\section{References}

Agarwal, R., \& Kimball, M. (2015). Breaking through the zero lower bound. IMF Working Paper WP/15/224. Washington: International Monetary Fund.

Ametrano, F. M. (2017). About bitcoin and blockchain: A cultural paradigm shift. Milano-Bicocca University. Bank of Italy, Rome. Retrieved from https:/www.bancaditalia. it/pubblicazioni/altri-atti-convegni/2016-tecnologiablockchain/Pres_Univ_Ametrano.pdf.

Bera, A. K., \& Jarque, C., M. (1981) Efficient tests for normality, homoscedasticity and serial independence of regression residuals: Monte Carlo Evidence. Economics Letters. 7(4), 313-18.

Berentsen, A., \& Schär, F. (2018). A short introduction to the world of cryptocurrencies. Federal Reserve Bank of St. Louis REVIEW. First Quarter, 100(1), 1-16.

Blockchains: The great chain of being sure about things . (2015). The Economist.

Bollerslev, T. (1986). Generalized autoregressive conditional heteroskedasticity. Journal of Econometrics. 31(3), 307327.

Bonneau, J., Miller, A., Clark, J., Narayanan, A., Kroll, J. A., Felten, E. W. (2015). SoK: Research perspectives and challenges for bitcoin and cryptocurrencies. IEEE Symposium on Security and Privacy.

Bourie, E., Azzi, G., \& Dyhrberg, A. (2016). On the returnvolatility relationship in the bitcoin market around the price crash of 2013. Retrieved from http://www. economics ejournal.org/economics/discussionpapers.

Braun, P. A., \& Mittnik, S. (1993) Misspecifications in vector autoregressions and their effects on impulse responses and variance decompositions. Journal of Econometrics 59, 319-41.

Christian, B., \& Beat, W. (2014). Bitcoin - The promise and limits of private innovation in monetary and payment systems.

Ciaian, P., Rajcaniova, M., \& Kancs, A. (2014). The economics of bitcoin price formation. Retrieved from http://arxiv.org/pdf/1405.4498.

Clements, M. P, \& Hendry, D. F. (1995), Forecasting in cointegrated system, Journal of Applied Econometrics, 10(2), 127-146.

Davies, D. (2014). The curious case of Bitcoin: Is Bitcoin volatileity driven by online research? $\mathrm{PhD}$ thesis, University of Victoria. Retrieved from https://www. uvic.ca/socialsciences/economics/assets/docs/honours/ Davies 1.pdf. Date of retrieval 1.08. 2017.

Davies, D. C. (2014). The curious case of bitcoin: Is bitcoin volatility driven by online search? An unpublished Thesis Submitted in Partial Fulfillment of the Requirements for the Degree of Bachelor of Arts, Honours in the Department of Economics. University of Victoria, Australia ().

Deloitte. (2016). Blockchain: Enigma, paradox opportunity, Deloitte Limited.

Dhrymes, P. J. (1971). Distributed Lags: Problems of estimation and formulation. Holden-Day, San Francisco.

Dickey, D. A., \& Fuller, W. A. (1979), Distribution of the estimators for autoregressive time series with a unit root, Journal of the American Statistical Association, 74(366), 427-431.

Dwyer, P, G. (2014). The economics of Bitcoin and similar private digital currencies. Journal of Financial Stability, 17, 81-91.

Dyhrberg,A. (2015). Bitcoin, gold and the dollar-Agarch volatility analysis. Finance Research Letters, Retrieved from www. sciencedirect.com/science/article/pii/S1544612315001038.

EBA. (2013). A report submitted to European Banking Authority. ISBN 978-92-95086-55-5doi:10.2853/65701.

Engle, R F. (1982). Autoregressive conditional heteroscedasticity with estimates of the variance of United Kingdom inflation. Econometrica. 50(4), 987-1007.

Engle, R. F., \& Yoo, B. S. (1987). Forecasting and testing in cointegrated systems, Journal of Econometrics, 35(1), 143-159.

Engle, R. F. (1983). Wald, likelihood ratio, and lagrange multiplier tests in econometrics. Intriligator, M. D.; Griliches, Z. Handbook of Econometrics. II. Elsevier. 
Estrada, J. C. S. (2017) Analyzing bitcoin price volatility. Submitted to the University of California, Berkeley. Retrieved from https:/www.econ.berkeley.edu/sites/ default/files/Thesis_Julio_Soldevilla.pdf.

European Banking Authority (2014). EBA Opinion on virtual currencies. EBA/Op/2014/08.

European Parliamentary Research Service. (2014). Bitcoin, market, economics and regulation. Retrieved from http://www.europarl.europa.eu/RegData/bibliotheque/ briefing/2014/140793/LDM_BRI\%282 014\%29140793_ REV1_EN.pdf

Extance, A. (2015). The future of cryptocurrencies: Bitcoin and beyond. Nature. 526(7571), 21-23.

Fernholz, T. (2015). Terrorism finance trackers worry ISIS already using bitcoin. Defense One. Retrieved from http:// www.defenseone.com/threats/2015/02/terrorism-financetrackers-worryisis-already-using-bitcoin/105345/.

Frankel, M. (2018). Bitcoin, Ethereum, and Ripple are just the beginning. Retrieved from https://www.fool.com/ investing/2018/03/16/how-many-cryptocurrencies-arethere.aspx.

Friedrich, A. H. (2007). Denationalisation of Money 20 Retrieved from http://www.iea.org. uk/sites/default/files/ publications/files/upldbook431 pdf. pdf.

Fuller, W. A. (1976). Introduction to Statistical Time Series. New York: John Wiley and Sons. ISBN 0-471-28715-6.

Gantori, S. (2017). Cryptocurrencies beneath the bubble. A report prepared by UBS AG and UBS Financial Services Inc. (UBS FS) and UBS Switzerland AG.

Halaburda, H., \& Sarvary, M. (2016). Beyond Bitcoin the economics of digital currencies Palgrave Mc. Millan.

Hamilton, J. D. (1994). Time Series Analysis. Princeton University Press.

Hamilton, J. D. (1994). Time series analysis, Princeton University Press. Chapter 11.

Hoffman, D. L., \& Rasche, R. H. (1996). Assessing forecast performance in a cointegrated system, Journal of Applied Econometrics, 11(5), 495-517.

Horne, C. F. (1915). The code of Hammurabi: Introduction. Yale University .

Hughes, E. (1993). A Cypherpunk Manifesto. Retrieved from http://www.activism.net/cypherpunk/manifesto.html

Hughes, S. J., \& Middlebrook, S. T. (2017). Advancing a framework for regulating cryptocurrency payments intermediaries, Retrieved from http://digitalcommons. law.yale.edu/yjreg/vol32/iss2/8

J. P., \& G. T . (2011), Virtual Currency: Bits and Bob, The Economist., Retrieved from http://www. economist.com/ blogs/babbage/2011/06/virtual -currency.
Jarque, C. M., \& Bera, A. K. (1980). Efficient tests for normality, homoscedasticity and serial independence of regression residuals. Economics Letters, 6(3), 255-259.

Jarque, C. M., \& Bera, A. K. (1981). Efficient tests for normality, homoscedasticity and serial independence of regression residuals: Monte Carlo evidence, Economics Letters. 7(4), 313-318.

Johansen, S., \& Juselius, K. (1990), Maximum likelihood estimation and inference on cointegration - with applications to the demand for money, Oxford Bulletin of Economics and statistics, 55(2), 169-210.

Johansen, S. (1991). Estimation and hypothesis testing of cointegration vectors in gaussian vector autoregressive models. Econometrica. 59(6), 1551-1580.

Kiyotaki, N., Wright, R. A search-theoretic approach to monetary economics. American Economic Review, 83(1), 63-77.

Kristoufek, L. (2013). Bitcoin meets google trends and wikipedia: Quantifying the relationship between phenomena of the internet era. Retrieved from https:// www.nature.com/articles/srep03415.

Lütkepohl, H. (2007). New introduction to multiple time series analysis, Springer, 63.

Maghyereh, A. (2004). Oil price shocks and emerging stock markets: A generalized VAR approach, International Journal of Applied Econometrics and Quantitative Studies, 1(2), 27-40.

Naka, A. \& Tufte, D. (1997). Examining impulse response functions in cointegrated systems, Applied Economics, 29(12), 1593-1603.

Nakamoto, S. (2008). Bitcoin: A peer-to-peer electronic cash system. Retrieved from https://bitcoin.org/bitcoin.pdf.

Narayanan, A., Bonneau, J., Felten, E., Miller, A., Goldfeder, S. (2016). Bitcoin and cryptocurrency technologies: A comprehensive introduction. Princeton: Princeton University Press.

Nelson, D., B., \& Cao, C. (1992). Inequality constraints in the univariate GARCH model. Journal of Business and Economic Statistics, 10(2), 229-235.

Pflaum, I., \& Hateley, E. (2014). A bit of a problem: National and extraterritorial regulation of virtual currency in the age of financial disintermediation. Georgetown Journal of International Law, 45(4). 1169-1214.

Phillips, P. C. B., \& Perron, P. (1988). Testing for a unit root in time series regression, Biometrika, 75, 335-346.

Plassaras, N. A. (2013). Regulating digital currencies: Bringing bitcoin within reach of the IMF. Chicago Journal of International Law, 14(1), 377-407.

Popper, N. (2015). Digital gold: The untold story of Bitcoin. London: Penguin. 
Popper, N. (2016). A venture fund with plenty of virtual capital, but no capitalist. The New York Times.

Raymaekers. (2014). Cryptocurrency Bitcoin: Disruption, challenges and opportunities. Journal of Payments Strategy \& Systems, 1-40.

Rotman, S. (2014). Bitcoin versus electronic money, World Bank, CGAP.

Said, S. E., Dickey, D. A. (1984): Testing for unit roots in autoregressive-moving average models of unknown order. Biometrika. 71, 599-607.

Seetharaman, A., Saravanan, S., Patwa, N., Mehta, J. (2017). Impact of bitcoin as a world currency. Accounting and Finance Research. 6(2), 230-246.

Sheridan, B. (2011). Bitcoins: Currengvo the Geeks. Retrieved from http://www.businessweek.com/magazine/ content/1126/b4234041554873.htm.

Stephenson, N. (1999). Cryptonomicon. Avon Books: New York.

Swan, M. (2015). Blockchain: Blueprint for a New Economy. O’Reilly Media: Sebastopol.

Tsukerman, M. (2015). Forthcoming. The block is hot: A survey of the state of bitcoin regulation and suggestions for the future (March 30, 2015). Berkeley Technology Law Journal, 30.

van Wijk, D. (2013). What can be expected from the Bitcoin?

$\mathrm{PhD}$ Thesis, Erasmus Uni versiteit Rotterdam. Retrieved from https://thesis.eur.nl/pub/14100/Final-version-ThesisDennis-van Wijk.pdf.

Vigna, P., \& Casey, M. (2015). The age of cryptocurrency: How bitcoin and digital money are challenging the global economic order (London: The Bodley Head).

Vigna, P., \& Casey, M. J. (2015). The age of cryptocurrency: How bitcoin and digital money are challenging the global economic order. New York: St. Martin's Press.

Walport M. (2015). Distributed ledger technology: Beyond Blockchain, HM Government Office of Science.

Walport.(2015). Distributed ledger technology: Beyondblock chain A report by the UK Government Chief Scientific Adviser. Retrieved from https://assets.publishing.service. gov.uk/government/uploads/system/uploads/attachment data/file/492972/gs-16-1-distributed-ledger-technology. pdf.

Wu, C, Vivek, K. (2013). The value of bitcoin in enhancing the efficiency of an investor's portfolio. Journal of Financial Planning, 27, 44-52.

Yermack, D. (2013). Is Bitcoin a real currency? An economic appraisal. NBER Working Paper Series.

Yli-Huumo, J., Ko, D., Choi, S., Park, S., Smolander, K. (2016). Where is current research on blockchain technology? A systematic review. PLoS ONE, 11(10). ,'Blockchains: The great chain of being sure about things". The Economist. 31 October 2015. 